\title{
Research on Safety Management of the Power Transmission and Distribution Construction Project
}

\author{
Fusheng Zhang \\ Jinzhou Power Supply Branch, State Grid Liaoning \\ Electric Power Supply Co. Ltd \\ Jinzhou, china \\ fushengzhoujz@163.com
}

\author{
Zhizhou Chen \\ Jinzhou Power Supply Branch, State Grid Liaoning \\ Electric Power Supply Co. Ltd \\ Jinzhou, china \\ Czz1980@163.com
}

\begin{abstract}
At present, with the development of society and economy, Transmission and Distribution Project is increasing. Compared with the general construction projects, Transmission and Distribution construction project diversity, fluidity and complexity characteristics. Because of Transmission and Distribution construction project these peculiarities make the construction process safety management becomes more important. This paper introduced the characteristics of Transmission and Distribution Construction on the project, Transmission and Distribution of the current construction project safety management to analyze the problems in order to solve these problems of Transmission and Distribution Construction Project Safety Management made some practical measures .
\end{abstract}

Keywords-transmission and distribution construction; security management; features; measures

\section{INTRODUCTION}

Safety is related to people's livelihood, a matter the success of enterprise, but also a prerequisite for a first-class enterprise is fundamental to the success of reform. Currently, the country is also the largest ongoing history of the world's infrastructure. Our annual capital investment accounted for about 15 percent of GDP. Employing up to 35 million, accounting for about onethird of industrial enterprises in the total employees strong. Scale construction of the huge investment and practitioners make the consequences of accidents are very serious, very huge losses every year due to accidents while employing thousands of people lost their lives, the direct economic loss of over a hundred million. Lower levels of safety production management has become an important factor in the country's economic development and hinder the development of social stability has become the focus of attention of the community.

Now, as China's rapid economic development, in order to meet the needs of citizens, the country's power grid is also developing rapidly, and therefore, Transmission and Distribution Line Project, more and more, and gradually gained in importance. Competition in the electricity market has intensified, the major power construction unit feel the pressure, accelerate the development of care their competitiveness, looking through their own reforms to adapt to the new requirements become nowadays economic development. But competitiveness is the key to how to improve on the Transmission and Distribution construction project management, security management of all construction projects can not be ignored, so the Transmission and Distribution construction is no exception, safety is always first[1]. How to strengthen the Transmission and Distribution construction project safety management work is especially important now.

Transmission and Distribution Project in the construction industry is a kind of high risk, high intensity operations[2-3]. Requires the ability to work at higher risk and strong liquidity staff working period, more dispersed personnel. In addition, it is also a great amount of work, the larger security management more difficult, there is quite a lot of risks. During construction of the Transmission and Distribution Project will always be a lot of large-scale accidents, especially high-voltage and extra high voltage overhead power line construction. This paper discusses the construction safety management policy Transmission and Distribution Project.

\section{THE STATUS QUO AND CHARACTERISTICS OF POWER}

TRANSMISSION AND DISTRIBUTION CONSTRUCTION PROJECT

\section{A. the status quo of Power Transmission and Distribution Construction Project}

(A) Transmission and Transformation Project refers to the poles buried in the ground under construction, the main effect of doing this is to prevent the poles receive external wind action in the case and put into use after the sinking or deformation occurs[4]. Transmission and Distribution Line construction quality directly affects its ability to occur after a good role in the work process. When the actual construction project, there are a lot of telephone poles because of the emergence of cracks in infrastructure, to sink or site means unreasonable and so on, during the construction of infrastructure projects, must be very strictly in accordance with the design drawings conduct, so that it can ensure the future of the building will have higher quality[5]. 
(B) Transmission and Distribution Project in terms of overhead line construction requirements. Check the preparation work before construction preparation work, arc detection, shrink lines and associated ancillary equipment. Wired construction are usually two types[6]. One is to put a drag; the other is pulling tension carried put. After the overhead line construction is completed, occasional inconsistencies between the lines radian case, or the case is not in the middle position hanging insulator, if the deviation is too large it should be adjusted accordingly. Radian deviation line conductors and lightning is generally controlled within a small error range.

\section{B. the characteristics of Power Transmission and Distribution Construction Project}

Transmission and Distribution Construction of the production is characterized by points, lines long, wide, highly mobile, highly dispersed, high risk. In the construction industry is a high-strength, high-risk operations. And general building construction project, the construction of high voltage and extra high voltage overhead power lines, higher security risk, more dispersed work surface, the greater the security management more difficult[7]. So do the Transmission and Distribution construction project safety management is even more important, Transmission and Distribution of the unique characteristics of the construction projects in the following areas:

(A) send the complexity substation construction projects. Transmission and Distribution complexity is an important feature of the construction project. In most cases, Transmission and Distribution construction projects are very poor in some geographical conditions, climate changing, complex geological and hydrological conditions of work places, and the staff are generally open field operations. Transmission and Distribution construction project complexity not only in these areas, the situation is very complicated trades, specifically in three areas. First, the type of work often is not fixed. Second, even if the same type of work, but because of work hours and work in different parts of the job content are different. Third, the same type of work, but due to the influence of different construction site, work environment, and job content are often different[8].

(B) send the diversity and distribution construction projects. Diversity is another distinctive characteristic feature of Transmission and Distribution construction project. The socalled wide diversity refers to the construction characteristics of the project, points, lines long. Wide project that involves many aspects of the expansion of the construction, renovation, new etc; points that operating point more; that is the length of a long line of very long lines[9]. These factors make the Transmission and Distribution construction project became a many processes, materials and equipment scheduling complex, highly integrated a construction project.

(C) personnel, equipment, mobility, frequent changes in the construction environment. With the power to carry out the separation of major reform, with the accelerated pace of power grid construction, renovation and expansion projects focused substation project construction launched a phenomenon, concurrent projects carried out on more. For builders substation, it means that the project has just been completed, it is necessary to quickly put them on to the next project, or a project builders to undertake tasks at the same time two or three items. Work environment includes a hazard, and the corresponding security facilities tend to be synchronized even behind the construction process. Furthermore, due to environmental changes frequently, resulting in construction workers readily adapt to the new environment in the process, by the impact of adverse conditions in the environment, so that the probability of danger increases.

(D) Harsh conditions of construction projects Transmission and Distribution Project. Because it is the job of the impermanence of the weather conditions outside. Because delivery of construction projects Transformation Project are working in the field, so when there is heavy rain or snow, etc. when bad weather is a safety hazard.

(E) construction work surface is narrow, cross-operating more and more dangerous high operating risks. Restricted land affected by the project, the construction process substations, high operating accounts for about $90 \%$, and because of the substation electrical equipment installation is relatively concentrated, the guard is not the time, prone to falls or falling objects and other accidents, can easily result in low Department damage electrical equipment. Substation electrical equipment due to the high value of the monomer, there will be no spare parts to replace, so in the event of damage to the equipment, in addition to direct greater losses, the impact on the duration of the particularly serious. Due to the progress of the needs and conditions of the actual construction constraints, often need more jobs, more team to start construction work in the same work surface, in a limited space to focus a lot of workers, materials, machinery and equipment for interchange operations, resulting in a limited time and space within the hazard highly concentrated, if protective measures properly, a types of work may cause other types of personnel to be hurt, easily lead to accidents. For example, civil engineering with the nail plate is not cleared up bar on the phenomenon of others, did not finish after the test capacitor electric power to put people phenomenon, debug string electric phenomena occur, and so on.

(F) Electrical secondary wiring, commissioning transmission capacity, easy to cause an electric shock, equipment accidents, power accident. This is the largest substation construction characteristics, electrical substation equipment more secondary measurement and control systems and information through a remote system is more complex, multi-cable wiring, easy to produce parasitic circuit wiring, check the live transmission work the slightest mistake will lead to a huge disaster, ranging from blown insurance, equipment, trips, while lead casualties, damage, power splitting and other serious accidents.

(G) a large number of migrant workers recruited by decreased the quality of the construction team. With the start of a large number of electric power construction projects, Transmission and Distribution Company had hired a large number of migrant workers, or dispatch workers to make up for their lack of construction forces. These workers safety and technical knowledge is poor, very superficial knowledge of safe operation, lack of self-protection. There are many workers from rural areas, by education and training less, relatively low quality, poor safety awareness, a sense of security, 
management and safety training too seriously, so that increases the likelihood of accidents, safety management and construction quality prone to problems.

\section{THE PROBLEMS OF TRANSMISSION AND DISTRIBUTION CONSTRUCTION PROJECT SAFETY MANAGEMENT}

Safety technology evolved into the technology needed technical security measures, which means taken for safety. In production activities, the workers in a variety of production environments and operating conditions, using a variety of equipment, tools and materials, there is a certain working environment for workers safety and health of unfavorable factors, or the use of machinery and equipment due to workers imperfect tool, it may cause injury or death of workers. In order to prevent these causes of accidents and the impact must take various measures, integration, security technology called all of these measures. Technical measures include content security guards wheel, presses, forging machines; safe start-up and fast lifts and parking facilities on lifting machinery; for handling job security or guarantee the discharge of the liquid floor resurfacing or repair; workers may guards arrived hole, pit, trench, lifts, etc. equipment; in the production area, workers are often in the past the location, access and temporary bridge for safety and set up; to avoid people falling to the ground and set the height of the fence, seat belts. Safety measures are important to ensure the safety of the production of construction and property from damage, must be highly valued. Also with the transmission line voltage increases, the tower heavier, higher and higher, the corresponding construction difficult. Tower Group established methods are integral lifting and hoisting slice. Slice currently used is lifting the suspension and floor cupola pole pole in two ways. Either way set by vertical tower must first consider the security issues. According to objective laws, to make a variety of vertical tower methods play a role in the premise of safety.

Engaged in hazardous industries is often simple labor, but also tend to be the most competitive in the market, the construction unit under realistic investment budget always talks about the security measures of civilization but also to the construction unit fee discount, still often do some flashy appearance to fight for what this award that prize, such as power construction subcontract some construction tasks, whose low cost, and who have a competitive edge. Current lack of clear, specific and workable laws to unify the height threshold, so as to solve the access problem, or something happens you can handle a few million, a low cost of risk.

Due to send complexity, diversity and mobility characteristics substation construction projects, making Transmission and Distribution construction project safety management work has become very difficult. Transmission and Distribution on the status of construction safety management of view, there is still the current security management, many problems, the situation is not optimistic. These problems are mainly reflected in the following aspects. First, Transmission and Distribution construction project worker safety consciousness, self-protection and accident avoidance capability is weak. Second, Transmission and Distribution construction project safety management system has not been implemented, illegal command and illegal operations wide phenomenon. Third, Transmission and Distribution construction project safety technology and process behind and can not meet the security needs of the new era. This is also a cause of construction accident-prone. Fourth, Transmission and Distribution construction project tools there are many problems, lurks a lot of security risks. Fifth, send the harsh construction environment variable, live working and high operating range and so on.

\section{MEASURES OF TRANSMISSION AND DISTRIBUTION CONSTRUCTION PROJECT SAFETY MANAGEMENT}

\section{Technical measures}

Strengthen safety management foundation Transmission and Distribution Line Construction. Construction projects in the Transmission and Distribution, Transmission and Distribution Line to do basic construction safety. For example, in earthwork excavation areas: For those who want to relax the soil loose pit slope pit mouth or set retaining plate; for easy water pit to be built in the vicinity of the drain to prevent the collapse pit; in rock When blasting to near bursting point for exploration of the environment, in order to avoid damage to the surrounding houses, roads or communication lines, blasting blasting personnel according to the normal procedure with blasting operations, thus ensuring the safety of construction workers and other self. In-situ concrete foundations: Before pouring the foundation construction must first build a platform for a solid platform, generally used in the steel-type log structures; casting staff to wear helmets, to pass up and down the ladder pit; installing steel When the template, the template spell first piece, and then the composition as a whole; put stones or during concreting should obey, not free to put in, in order to avoid an accident; when using an electric vibrator to use good insulated power cable, When vibrators overheating or stop the job in time to cut off the power supply.

Strengthening the transmission line tower group established safety management. In order to meet the needs of social development, Transmission and Distribution Construction voltage power transmission line to the higher level also, the tower higher and higher, heavier, more difficult construction, risk is also higher. In the Transmission and Distribution construction project must strengthen the transmission line tower group established safety management. For example, when assembled, first thing to note flat construction of the base surface, to ensure straight rod drained same direction as the central axis of the line, so that the horizontal angle bisector angle with the central axis aligned; when the tower assembly to the extent possible fragmentation assembled in lifting vertically downward, and for the overall lifting of the Eiffel Tower, piece together the time to use the rope to control tower to avoid dumping wounding accident.

Strengthen safety management work put tight line construction. In the Transmission and Distribution construction project, put tight line construction is also an important part of safety management. For example, the "dry" type Tower of cable wires do not need to set up temporary, while the other tower and ground wires have set up a temporary cable; the tight line behind faced aiming for when to lay tight line tower Pro aiming too round; tight line after the job is completed, in 
addition to tight line tower installation program does not require the attachment of other accessories straight tower installation process should be carried out and, after installation, you want in a timely manner in the vicinity of tight straight line tower In turn round the tower Pro aiming operation.

\section{Management measures}

Adhere to the "prevention" is the key to transforming operational team to achieve safe production. Some of the "prevention" consciousness stays in form, a relatively large number of post-management and response measures enacted, fewer precautions beforehand, especially for accident analysis with a chance of making it less predictable. Adhere to the "prevention" of safety management team, the following aspects should be carried out: the introduction of other advanced security management team, combined with their actual development of an effective management system. Efforts to strengthen the equipment inspections, regular meals are not just seeking a broad area will come to every point, really good team safety activities. Expected to carry out accident and antiaccident exercises should be strict requirements. The number of exercises should be less not more, in the form of on-site simulation exercises should focus on the pursuit of the process of the exercise, remember not to exercise this as a seminar to carry out activities; strengthen the construction of the control and supervision of foreign security personnel to take concrete and effective security measures before they apply for work permits.

In practice how to make every team member to comply with rules and regulations, strictly in accordance with the site operating procedures and work instructions execution, knowledge of the rules and procedures rely heavily on team members. Unsafe behavior is an important cause of the accident, a large number of unsafe behavior will inevitably lead to an accident.

In the scene firmly built three defense, the first line of defense is a secure facility, the second line of defense is the security technology, the third line of defense is the safe custody. In addition, you should also pay attention to the squad to do management and focus on remediation of labor discipline. Give full play to the role of project manager in the construction of safe, truly pipe producers, pipe safety. The project manager in place conditions included in the regular content security checks.

To do a good job security management team must be from the usual start, do a good job training. Also by accident expected to carry out serious and pragmatic and anti-accident maneuver training, improve the ability of team members to deal with the accident, the only way to shut always has security incident handling process. Organization for Security and production of key personnel, such as team leader, responsible person, security guardians, timely correct implementation of safety procedures for training regime. Special types must be certified, and timely review.

Because of the indirect nature and content of the work of the scalability of its achievements vagueness, work efficiency, it could produce paralysis of thought and energy-saving mentality. We can say that strict safety management is determined by the nature of the decision. The technology, safety, system highly placed to understand the law, follow the law must be strictly enforced. Educate the workers to establish a strong "legalization" concept, so that every worker in every aspect of production, each process, each link can act according to the rules and regulations. Rigorous technical solutions and safety technology, is the fundamental guarantee for safe production. The majority of technical staff responsible for the technology to ensure safety of the sacred mission and responsibility requires that they work in a serious, meticulous, to construction workers come up with a viable, safe and reliable guidance documents.

\section{CONCLUSION}

In view of the Transmission and Distribution construction projects operating characteristics of high-risk and high-strength Transmission and Distribution construction project safety management is even more important. Current security management Transmission and Distribution construction project, there are still many problems, so to strengthen the safety management of power transmission and transformation of all aspects of the construction project, to ensure personal throughout the Transmission and Distribution construction project from a technical and management aspects safety and security equipment.

\section{REFERENCES}

[1] G. Zhao, G. Yang, X. Li, "Discussion on Power Transmission and Transformation Project Electromagnetic Impact and its EIA Problems,' Electric Power Environmental Protection, vol. 4, pp. 16-19,2007

[2] L. Z. Zheng, "Research on Electromagnetic Radiation of High-Voltage Transmission Facilities and Environmental Impact Assessment," Journal of Suzhou University, vol. 2, pp. 125-127,2009

[3] Q. Reng, Y. Tan, K. H. Hu, “ Discussion on the Problems and Suggestions in the Environmental Management of Power Transmission and Distribution Projects," Sichuan Environment ,pp. 133-135,2010

[4] L. Z. Zheng, “ Research on Electromagnetic Radiation of High-Voltage Transmission Facilities and Environmental Impact Assessment," Journal of Suzhou University, pp. 125-127,2009

[5] W. C. Ren, “ Impacts of Electromagnetic Radiation from High Voltage Power Transmission and Distribution Project on Environment and People Health and its Control," Environmental Science Survey , vol. 28, pp. 61-63,2009

[6] C. C. Zhai, “ Electromagnetic Effects on Environmental of Power Transmission Engineering in Urban District," Guangdong Power Transmission Technology, pp. 18-20,2007

[7] D. Wenzhan, "A method of multiobjective synthetic evaluation based on artificial neural networks and its applications," Syst. Eng. Theor. Pract, vol. 19, pp. 30-33,1999

[8] B. Irie, , S. Miyake, " Capabilities of three-layered perceptrons," Proceedings of the IEEE International Conference on Neural Network, vol. 1, pp. 641-648,1998

[9] H. Suguangquan, "Land resource suitability evaluation in ore district," Prog. Geogr , vol. 17, 39-46,1998 